\title{
Liver Iron Concentration
}

National Cancer Institute

\section{Source}

National Cancer Institute. Liver Iron Concentration. NCI Thesaurus. Code C124065.

A measurement of the concentration of iron in the liver as an estimate of body iron load. 